\title{
Physiological and Biochemical Responses to Drought Stress and Subsequent Rehydration in the Symbiotic Association Peanut-Bradyrhizobium sp.
}

\author{
Ana Furlan, Analía Llanes, Virginia Luna, and Stella Castro \\ Departamento de Ciencias Naturales, Facultad de Ciencias Exactas, Físico-Químicas y Naturales, Universidad Nacional de Río Cuarto, \\ Ruta 36, Km. 601, Río Cuarto, 5800 Córdoba, Argentina \\ Correspondence should be addressed to Stella Castro, scastro@exa.unrc.edu.ar
}

Received 20 April 2012; Accepted 12 July 2012

Academic Editors: H. P. Singh and P. Soengas

Copyright (๑) 2012 Ana Furlan et al. This is an open access article distributed under the Creative Commons Attribution License, which permits unrestricted use, distribution, and reproduction in any medium, provided the original work is properly cited.

Drought stress is one of the most important environmental factors that regulate plant growth and development and limit its production. Peanut (Arachis hypogaea L.) is an agriculturally valuable plant with widespread distribution in the world serving as a subsistence food crop as well as a source of various food products. The aims of this work were to evaluate growth and nodulation as well as some physiological and biochemical stress indicators in response to drought stress and subsequent rehydration in the symbiotic association peanut-Bradyrhizobium sp. SEMIA6144. Drought stress affected peanut growth reducing shoot dry weight, nodule number, and dry weight as well as nitrogen content, but root dry weight increased reaching a major exploratory surface. Besides, this severe water stress induced hydrogen peroxide production associated with lipid and protein damage; however, the plant was able to increase soluble sugar and abscisic acid contents as avoidance strategies to cope with drought stress. These physiological and biochemical parameters were completely reversed upon rehydration, in a short period of time, in the symbiotic association peanut-Bradyrhizobium sp. Thus, the results provided in this work constitute the initial steps of physiological and biochemical responses to drought stress and rehydration in this nodulated legume.

\section{Introduction}

Peanut (Arachis hypogaea L.) is grown as an important crop in a wide range of environments between latitudes of $40^{\circ} \mathrm{N}$ and $40^{\circ} \mathrm{S}$. Two-thirds of the global production occurs in rainfed areas of the semiarid tropics which are characterized by unpredictable periods of water deficit [1]. Along with the United States and China, Argentina is one of the major exporters of peanut for human consumption [2]. However, the crop production area suffers intermittently water deficit periods almost every year [3]. Peanut flowering and pod filling are quiet sensitive to drought stress [4], thus water deficit periods affecting these phenological stages may have a large negative impact on yield.

Drought stress causes cellular dehydration as a consequence of water release from cytosol and vacuoles to the apoplast. The plant responses to water stress include changes in stomatal conductance, growth, osmolyte accumulation, and expression of specific genes. In these processes, the abscisic acid (ABA) is defined as the major stress hormone due to its rapid accumulation in severe conditions and participation in physiological and biochemical processes that allow plants to survive to this challenge [5]. Sharp and LeNoble [6] suggested that ABA may be helpful to maintain shoot and root limited growth under water deficit. Understandably, maintenance of root growth under this condition would enhance drought tolerance due to an increased capacity of water uptake. On the other hand, both the maintenance of plant functions at a low water potential and their recovery after rehydration contribute to high yield achievement under cyclic drought periods [7]. Plant recovery after rehydration is an essential trait for plant survival and reflects the balance between damaged structures reconstruction and adequate metabolism restoration [8]. Therefore, comprehensive studies about plant responses to rehydration are essential. 
It is well known that reactive oxygen species (ROS) production is linked with normal metabolic processes such as aerobic metabolism [9] and photosynthesis [10]. However, its production is increased under abiotic stress conditions through mechanisms such as the inhibition of $\mathrm{NADP}^{+}$regeneration, Mehler reaction, and photorespiration. Under these conditions, $\mathrm{ABA}$ accumulation triggers superoxide anion $\left(\mathrm{O}_{2}{ }^{\bullet-}\right)$ and hydrogen peroxide $\left(\mathrm{H}_{2} \mathrm{O}_{2}\right)$ production through inhibition of $\mathrm{CO}_{2}$ uptake and alteration in transport electron chain in chloroplasts [11]. In addition, $\mathrm{H}_{2} \mathrm{O}_{2}$ has been detected in $\mathrm{ABA}$ response as a mediator of stomatal closure [12] or inhibition of stomatal opening [13]. Finally, the antioxidant system, which includes enzymatic and nonenzymatic compounds, is capable of detoxifying ROS under stress conditions. However, when ROS production exceeds the antioxidant activity, the cell can enter in an oxidative stress expressed by lipid peroxidation and protein and DNA oxidative damage [14]. Akcay et al. [15] demonstrated that drought impaired growth and induced oxidative damage in peanut seedlings: however, oxidative damage as well as ABA accumulation in nodulated peanut is essentially unexplored.

Most of legumes, including peanut, have particular features in response to drought such as reduced rates of nodulation and biological nitrogen fixation (BNF) [16]. In nodules, drought stress increases soluble sugars and decreases solute potential in cells maintaining the turgor at a low water potential. The effects of drought stress on biological nitrogen fixation have been focused on three factors: carbon metabolism, nodule permeability to oxygen, and nitrogen feedback. A common factor that links these three factors is the sensitivity of phloem flow to plant water status. Because of the high sensitivity of nodules to phloem volumetric flow, there are a number of possible consequences resulting in a high sensitivity of nitrogen fixation to drought stress [17]. Nodulated peanut showed differential tolerance responses to drought stress conditions depending upon the genotype [16]; however, the effects of water deficiency and subsequent rehydration on the symbiotic association peanutBradyrhizobium sp have not been studied yet. Taking into account the agronomic importance of this symbiotic pair, information on those responses would provide a valuable contribution to the topic. Therefore, the aims of this work were to evaluate growth and nodulation as well as some physiological and biochemical stress indicators in response to drought stress and subsequent rehydration in the symbiotic association peanut-Bradyrhizobium sp.

\section{Materials and Methods}

2.1. Plant Material and Treatments. Seeds of peanut (Arachis hypogaea L.) cv Granoleico (Criadero El Carmen, General Cabrera, Córdoba, Argentina) were surface sterilized [18] and pregerminated in Petri dishes for $96 \mathrm{~h}$. Pregerminated seeds were transferred to pots which have a diameter of $8 \mathrm{~cm}$ and height of $12 \mathrm{~cm}$. Each pot was filled with $200 \mathrm{~g}$ of sterile volcanic sand. Plants were grown in a controlled growth chamber (light intensity: $200 \mu \mathrm{mol} \mathrm{m}^{-2} \mathrm{sec}^{-1}$; 16-h day $/ 8$-h night cycle; $28^{\circ} \mathrm{C}$; and a relative humidity of $50 \%$ ).
The strain Bradyrhizobium sp. SEMIA6144, able to infect peanut plants, was provided by MIRCEN, Porto Alegre, Brazil. Seven days after sowing, plants were inoculated with $4 \mathrm{~mL}$ of Yeast Extract-Manitol (YEM) culture containing $10^{8}$ cells $\mathrm{mL}^{-1}$. Plants were irrigated twice a week alternately with distilled water and Hoagland nutrient solution without nitrogen [19] in order to keep the field capacity (13\%), which was determined through pressure-plate method [20]. Thirty days after sowing (DAS) plants in flowering phase (R1) [21] were separated at random into three experimental groups (a) control: plants were kept under normal irrigation conditions, (b) drought stress: the irrigation was suspended until plants exhibit wilting symptoms, (c) rehydrated: plants subjected to drought stress were reirrigated.

2.2. Plant Water Status. Along the experiment, the water condition of plants subjected to different treatments was measured in the second expanded leave from the top of the main stem of each plant collected between 10-12 a.m. Relative water content (RWC) was determined by weighting the leaves, afterwards imbibition (tissues floated in distilled water for $8 \mathrm{~h}$ ) and finally oven dried at $60^{\circ} \mathrm{C}$ [22]. Osmotic potential $\left(\Psi_{\mathrm{o}}\right)$ was determined by measuring the freezing point of samples using an osmometer (Semi Micro K-700, Knauer) [23]. Also, osmotic potential was also measured in nodules $(100 \mathrm{mg})$ which were pooled of different plants at the end of the stress and rehydration periods. Transpiration efficiency (TE) was determined following the method of Udayakumar et al. [24]. Briefly, biomass of plants was recorded at the beginning and at the end of treatments. The difference between these two values was related to the cumulative water transpired, which was daily measured by weighing the pot plants corresponding to the three treatments. This value was compared with pots containing only volcanic sand to calculate the difference between evapotranspiration and transpiration. Finally, TE was calculated as follows: $\left(\mathrm{DW}_{\text {final }}-\mathrm{DW}_{\text {initial }}\right) / \mathrm{CWT}$, where $\mathrm{DW}_{\text {final }}$ is the dry weight of plants recorded at the end of the experiment, while $\mathrm{DW}_{\text {initial }}$ is the dry weight of plants recorded at beginning of it, and CWT is the cumulative water transpired along the experiment.

\subsection{Growth and Biological Nitrogen Fixation Parameters.} Treated plants were harvested at the end of the stress and rehydration periods (44 and 47 DAS, resp.) and control plants were collected at the end of the experiment (47 DAS). Then, they were used for the determination of shoot, root and nodule dry weight (Shoot DW, Root DW, and Nodule $\mathrm{DW})$, normalized nodule weight (NNW), nodule number, and shoot nitrogen content (SNC) after drying the samples at $70^{\circ} \mathrm{C}$ during $72 \mathrm{~h}$. The nitrogen content in shoots was determined according to the procedure proposed by Nelson and Sommers [25].

2.4. Drought Stress Indicators. Samples of roots, leaves, and nodules of treated plants (44 and 47 DAS) were immediately frozen in liquid nitrogen and stored at $-80^{\circ} \mathrm{C}$ for further analysis. The amount of total chlorophyll was determined 
by the method described by Arnon [26]. Briefly, about $0.1 \mathrm{~g}$ of peanut leaves was placed into a mortar, and the tissues were grinded to fine pulp after the addition of $80 \%$ acetone. The resulting extract was transferred to a Buchner funnel containing a pad of Whatman filter paper. While filtering the extract, the grinding of the leaves pulp was repeated to adjust the final volume of the filtrate to $10 \mathrm{~mL}$. The optical density of the chlorophyll extract was read with a spectrophotometer set at $652 \mathrm{~nm}$. The amount of total chlorophyll present in the extract was calculated on the basis of $\mu \mathrm{g}$ of chlorophyll per gram of leaf tissue, according to the following equation:

$$
\begin{aligned}
& \text { Total chlorophyll } \\
& \quad=\left[\left(\mathrm{OD}_{652} \times 1000\right) / 3.45\right] \times 10 \mathrm{~mL} / 1000 \times 0.1 \mathrm{~g} .
\end{aligned}
$$

Total soluble sugar concentration was determined in leaves and nodules. First, the sample ( $1 \mathrm{~g}$ for leaves and $0.3 \mathrm{~g}$ for nodules) was boiled in 5 volumes of $80 \%(\mathrm{v} / \mathrm{v})$ ethanol for 5 minutes. Then, the fifth part of the alcoholic solution was evaporated at $80^{\circ} \mathrm{C}$, and the residue was resuspended in 20 volumes of distilled water [27]. Finally, sugar content of the resulting solution was determined by Dische [28]. Abscisic acid content was measured according to technique of Zhou et al. [29]. Briefly, $150 \mathrm{mg}$ of plant material was homogenized with liquid nitrogen in an acid extraction solvent $(\mathrm{pH} 2.8-$ 3). As standard $5 \mathrm{ng}$ of [2H6]-ABA (J.D. Chen, USDAARS of Beltsville, Maryland, USA) was added. The aqueous phase was purified by adding an equal volume of ethyl acetate and organic phase was evaporated at total drying at $35^{\circ} \mathrm{C}$. Extract was resuspended in $100 \mu \mathrm{L}$ of methanol $(100 \%)$, placed in specific vials, and $10 \mu \mathrm{L}$ of each sample was used to determine ABA content by liquid chromatography (LC) (Waters, New York, USA) tandem mass spectrometry (MS-MS) (Micromas, Manchester, UK) with a monitoring software (Masslink 4.1).

\subsection{Hydrogen Peroxide Production and Oxidative Stress Indi-} cators. Hydrogen peroxide was measured spectrophotometrically after reaction with KI [30]. Leaves were homogenized in liquid nitrogen with $0.1 \%$ trichloroacetic acid (TCA). The homogenate was centrifuged at $10,000 \mathrm{~g}$ for $20 \mathrm{~min}$ to yield a crude extract. The reaction mixture consisted of $0.16 \mathrm{~mL} 0.1 \%$ TCA leaf or nodule extract supernatant, $0.16 \mathrm{~mL}$ of $100 \mathrm{mM} \mathrm{K}$-phosphate buffer, and $0.68 \mathrm{~mL}$ reagent $(1 \mathrm{M} \mathrm{KIw} / \mathrm{v}$ in fresh double-distilled water). The reaction was developed for $1 \mathrm{~h}$ in darkness and absorbance measured at $390 \mathrm{~nm}$. The amount of hydrogen peroxide was calculated using a standard curve prepared with known concentrations of $\mathrm{H}_{2} \mathrm{O}_{2}$. The level of lipid peroxides was determined as malondialdehyde (MDA) content by the thiobarbituric acid (TBA) reaction, as described by Heath and Packer [31]. Samples of leaves or nodules $(0.3 \mathrm{~g})$ were homogenized in $3 \mathrm{~mL}$ of $0.1 \%(\mathrm{w} / \mathrm{v})$ TCA solution. The homogenate was centrifuged at $10,000 \mathrm{~g}$ for $5 \mathrm{~min}$, and $0.75 \mathrm{~mL}$ of $20 \%$ TCA containing $0.5 \%(\mathrm{w} / \mathrm{v})$ TBA was added to a $0.75 \mathrm{~mL}$ aliquot of the supernatant. The mixture was heated at $95^{\circ} \mathrm{C}$ for $30 \mathrm{~min}$, quickly cooled on ice, and then centrifuged at $10,000 \mathrm{~g}$ for $15 \mathrm{~min}$. The sample was measured at $532 \mathrm{~nm}$ and corrected by the nonspecific absorption at $600 \mathrm{~nm}$.
The concentration of MDA was calculated using an extinction coefficient of $155 \mathrm{mM}^{-1} \mathrm{~cm}^{-1}$. Protein carbonyl content was measured by derivatization with 2,4dinitrophenylhydrazine according to Levine et al. [32] with some modifications. Proteins were extracted from $0.25 \mathrm{~g}$ of leaves or nodules with $2.5 \mathrm{~mL}$ of $100 \mathrm{mM}$ potassium phosphate (pH 7.0), 0.1\% (v/v) Triton X-100, 1 mM Na $a_{2}$ EDTA, and $2.5 \mathrm{mg}$ of leupeptin to prevent proteolysis of oxidized proteins during sample preparation. After precipitation of possible contaminating nucleic acids in the samples with $1 \%(\mathrm{w} / \mathrm{v})$ streptomycin sulfate, an aliquot of $0.4 \mathrm{~mL}$ of the extracts was reacted with $0.1 \mathrm{~mL}$ of $20 \mathrm{mM}$ dinitrophenylhydrazine in $2 \mathrm{M} \mathrm{HCl}$ and another aliquot (control) with $0.1 \mathrm{~mL}$ of $2 \mathrm{M} \mathrm{HCl}$ for $1 \mathrm{~h}$, with vigorous shaking every 10 to $15 \mathrm{~min}$. Proteins were then precipitated with $10 \%$ $(\mathrm{w} / \mathrm{v})$ TCA, and the pellet was washed four times with $1: 1(\mathrm{v} / \mathrm{v})$ ethanol: ethyl acetate. Precipitated proteins were solubilized in $6 \mathrm{M}$ guanidine- $\mathrm{HCl}(\mathrm{pH} 4.5)$ by incubation for 30 min with shaking. The insoluble material was removed by centrifugation, and the absorbance of the hydrazones (derivatized carbonyls) was measured at $370 \mathrm{~nm}$. To obtain more accurate results, the amount of protein to be analyzed for carbonyl content was adjusted to $0.5 \mathrm{mg}$ in all samples.

2.6. Statistical Analysis. The data were analysed using ANOVA and LSD Fisher's test at $P \leq 0.05$. Factorial design (days and treatments were considered as factors) was utilized for RWC and $\Psi_{0}$ analysis. Prior to the test of significance, the normality and homogeneity of variance were verified using the modified Shapiro-Wilk and Levene tests, respectively. If homogeneity of variance was not given, data were transformed using an appropriate function.

\section{Results}

3.1. Establishment of Plant Water Status. The results obtained of the parameters related to plant water status such as relative water content (RWC) (Figure 1(a)) and osmotic potential ( $\Psi_{\mathrm{o}}$ ) (Figure 1(b)) kept quite constant in control plants along the experiment. These parameters significantly decreased reaching the lowest values when wilting symptoms were observed in stressed plants (approximately fourteen days from the beginning of the experiment). In rehydrated plants, RWC and $\Psi_{0}$ values were similar to control plants after three days of rewatering. Nodule $\Psi_{0}$ corresponding to control, stressed and rehydrated plants were $-0.87 \pm$ $0.02 ;-1.21 \pm 0.01$ and $-0.74 \pm 0.08$, respectively, being the value of stressed plants significantly different to control and rehydrated ones. At harvest, the $\Psi_{0}$ values were used as indicators of the plant water status for the physiological and biochemical determinations carried out in leaves and nodules. TE is used as a water used balance and biomass production indicator under stress conditions. TE and its related variables did not show significant differences in both treatments compared with control. Although differences were not significant, TE and its components were lower in stressed and rehydrated plants than in control ones (Table 1). 


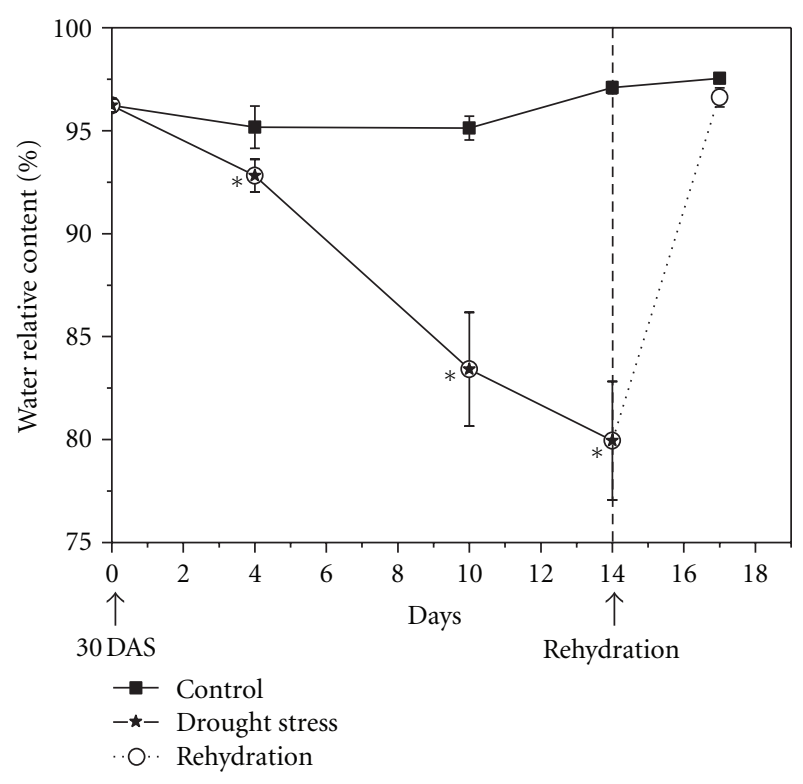

(a)

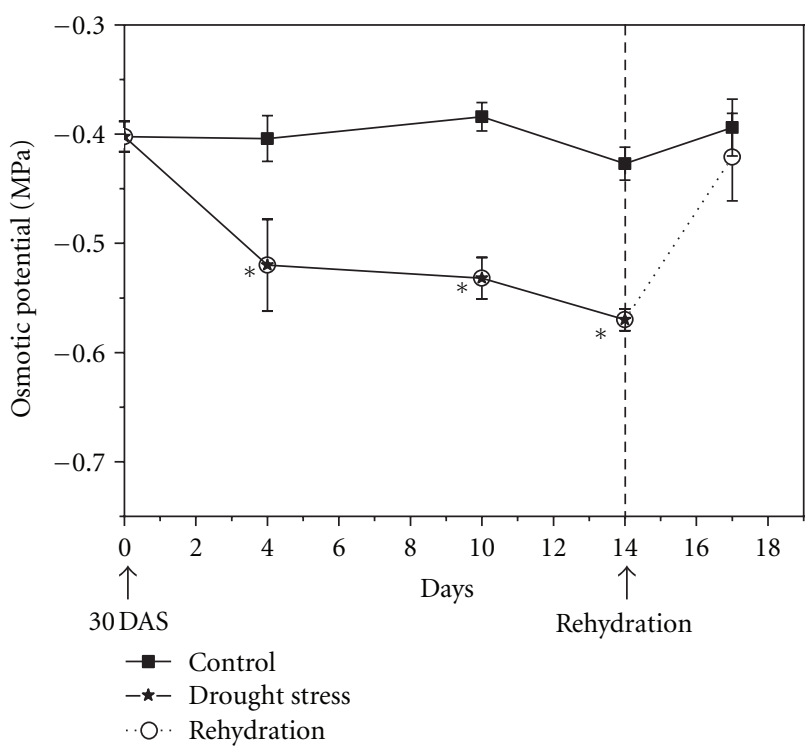

(b)

FIGURE 1: Water status of leaves of peanut plants exposed to drought stress and rehydration. Water relative content (a) and osmotic potential (b). Values are means $\pm \operatorname{SE}(n=10)$. ${ }^{*}$ Indicates significant differences at $P<0.05$ according to LSD Fisher's test.

3.2. Estimation of Growth and Biological Nitrogen Fixation in Peanut-Bradyrhizobium sp. Symbiosis under Drought Stress Condition. At the beginning of the experiment, peanut plants (30 DAS) had an average shoot and root DW of $471.48 \pm 34.53$ and $60.31 \pm 11.88 \mathrm{mg}$, respectively. After exposing the plants to drought stress they showed wilting symptoms (flaccidity and modifications in leafangle arrangement), while rehydrated plants recovered leaf turgor. At harvest, shoot DW decreased and root DW was significantly higher in stressed and rehydrated plants than in control plants, causing an increase in root/shoot ratio
TABLE 1: Effects of drought and rehydration on the transpiration efficiency parameters.

\begin{tabular}{lccc}
\hline Treatments & $\mathrm{TE}\left(\mathrm{g} \mathrm{mL}^{-1}\right)$ & $\mathrm{CWT}(\mathrm{mL})$ & $\mathrm{DW}_{\text {final }}-\mathrm{DW}_{\text {initial }}(\mathrm{g})$ \\
\hline Control & $0.023 \pm 0.005^{\mathrm{a}}$ & $19.82 \pm 3.23^{\mathrm{a}}$ & $0.37 \pm 0.04^{\mathrm{a}}$ \\
$\begin{array}{l}\text { Drought } \\
\text { stress }\end{array}$ & $0.023 \pm 0.007^{\mathrm{a}}$ & $16.44 \pm 5.88^{\mathrm{a}}$ & $0.31 \pm 0.05^{\mathrm{a}}$ \\
Rehydration & $0.015 \pm 0.004^{\mathrm{a}}$ & $16.30 \pm 5.76^{\mathrm{a}}$ & $0.24 \pm 0.08^{\mathrm{a}}$ \\
\hline
\end{tabular}

TE: transpiration efficiency, CWT: cumulative water transpired in the stress period, $\mathrm{DW}_{\text {final }}$ : dry weight of plants recorded at the end of the stress period; $\mathrm{DW}_{\text {initial }}$ : dry weight of plants recorded at beginning of the stress period. Values are means \pm S.E. $(n=6)$. Different letters in each column indicate significant differences at $P<0.05$ according to LSD Fisher's test.

TABLE 2: Effects of drought stress and rehydration on peanut growth.

\begin{tabular}{lccc}
\hline Treatments & $\begin{array}{c}\text { Shoot DW } \\
(\mathrm{mg})\end{array}$ & $\begin{array}{c}\text { Root DW } \\
(\mathrm{mg})\end{array}$ & Root/Shoot ratio \\
\hline $\begin{array}{lccc}\text { Control } \\
\text { Drought }\end{array}$ & $506.93 \pm 50.20^{\mathrm{a}}$ & $74.64 \pm 10.57^{\mathrm{a}}$ & $0.090 \pm 0.007^{\mathrm{a}}$ \\
stress & & $121.53 \pm 10.12^{\mathrm{b}}$ & $0.183 \pm 0.019^{\mathrm{b}}$ \\
Rehydration & $639.36 \pm 49.99^{\mathrm{b}}$ & $113.75 \pm 6.70^{\mathrm{b}}$ & $0.146 \pm 0.019^{\mathrm{b}}$ \\
\hline
\end{tabular}

Values are means \pm S.E. $(n=12)$. Different letters in each column indicate significant differences at $P<0.05$ according to LSD Fisher's test.

in stressed and rehydrated plants (Table 2). Nodule number and DW significantly decreased in stressed and rehydrated plants. The values of NNW, obtained from the shoot DW and nodule DW ratio, did not show differences among treatments indicating that both values are positively correlated $(r=0.8)$ (data not shown). The SNC showed a significant reduction in stressed and rehydrated plants compared with control ones (Table 3).

3.3. Effect of Drought Stress on Chlorophyll, Sugar, and $A B A$ Contents. Chlorophyll content remained unchanged in plants exposed to all treatments (Figure 2). Total soluble sugar increased in stressed plants leaves compared with rehydrated and control plants. In stressed plants nodules, soluble sugar content increased in $30 \%$, while rehydrated plants showed an intermediate value related to other treatments (Figure 3). ABA endogenous content showed a significant increase in leaves and roots of stressed plants compared with control ones, reaching higher values in leaves. After rehydration, plant $\mathrm{ABA}$ levels were similar to control plants (Figure 4).

3.4. Influence of Drought Stress on $\mathrm{H}_{2} \mathrm{O}_{2}$ Production, Lipid Peroxidation, and Protein Oxidation. Hydrogen peroxide production increased in leaves and nodules of plants subjected to drought stress. After rehydration, $\mathrm{H}_{2} \mathrm{O}_{2}$ content was similar to well-irrigated plants (Figure 5(a)). Lipid peroxides (quantified as MDA content) increased in leaves and nodules of peanut plants exposed to drought stress (Figure 5(b)). Carbonyl groups content increased only in leaves, while in nodules, this value was similar to control plants (Figure 5(c)). In rehydrated plants, the indicators of 
TABLE 3: Influence of drought stress and rehydration on peanut nodulation and nitrogen content.

\begin{tabular}{lcccc}
\hline Treatments & Nodule number & Nodule DW $(\mathrm{mg})$ & NNW & SNC $\left(\mathrm{mg} \mathrm{plant}^{-1}\right)$ \\
\hline Control & $41.85 \pm 2.92^{\mathrm{a}}$ & $22.24 \pm 2.62^{\mathrm{a}}$ & $0.018 \pm 0.003^{\mathrm{a}}$ & $23.52 \pm 2.84^{\mathrm{a}}$ \\
Drought stress & $29.15 \pm 1.50^{\mathrm{b}}$ & $15.83 \pm 1.08^{\mathrm{b}}$ & $0.019 \pm 0.001^{\mathrm{a}}$ & $10.14 \pm 1.88^{\mathrm{b}}$ \\
Rehydration & $33.57 \pm 2.14^{\mathrm{b}}$ & $16.65 \pm 1.37^{\mathrm{b}}$ & $0.023 \pm 0.003^{\mathrm{a}}$ & $10.42 \pm 0.43^{\mathrm{b}}$ \\
\hline
\end{tabular}

NNW: normalized nodule weight; SNC: shoot nitrogen content. Values are means \pm S.E. $(n=12)$. Different letters in each column indicate significant differences at $P<0.05$ according to LSD Fisher's test.
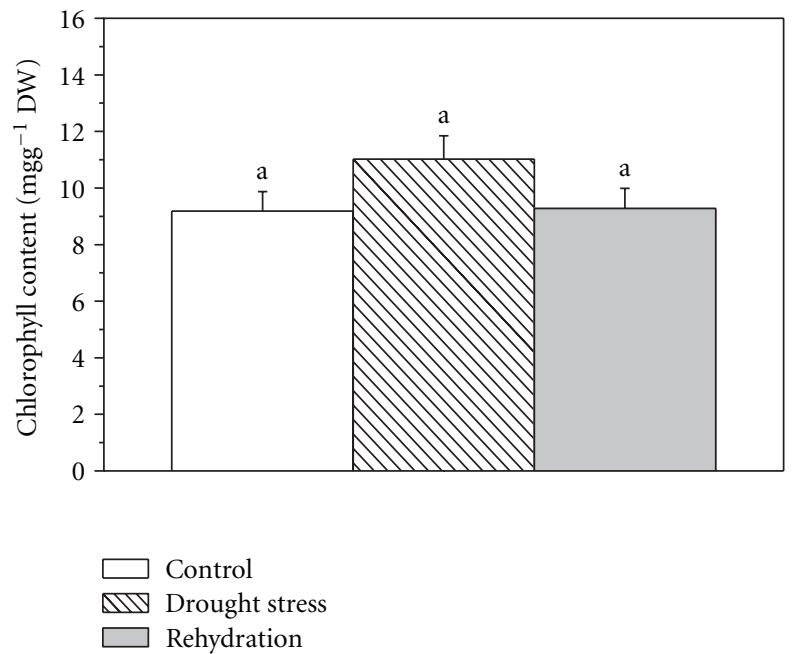

Figure 2: Chlorophyll content in peanut plants exposed to drought stress and rehydration. Values are means \pm SE $(n=10)$. Different letters indicate significant differences at $P<0.05$ according to LSD Fisher's test.

oxidative stress reached the control values in leaves and nodules at the end of the rehydration period (three days).

\section{Discussion}

In general, drought stress reduces shoot growth through effects on plant water status, photosynthesis, and leaf expansion, whereas root growth can achieve different responses [33]. Therefore, an increased root/shoot ratio acts as an index that reflects changes induced by drought stress as differential growth rates between organs. In this work, peanut plants subjected to severe water stress (leaf $\Psi_{0}=-0.56 \mathrm{MPa}$ ) showed a decreased shoot DW and an increased root DW. These results are in agreement with those found by Puangbut et al. [34], who reported an increased root DW related to high root density and length. In addition, peanut ability to keep a viable root system during water stress is required for crop drought tolerance.

It is well-documented that abiotic stress affects nodule development as well as nitrogen fixing activity which reduces the $\mathrm{N}$ contribution to legume growth [31]. Drought stress is one of the major factors affecting nitrogen fixation by legume-Rhizobium symbiosis. Several mechanisms have been previously reported to be involved in the physiological response of symbiotic nitrogen fixation to drought stress,

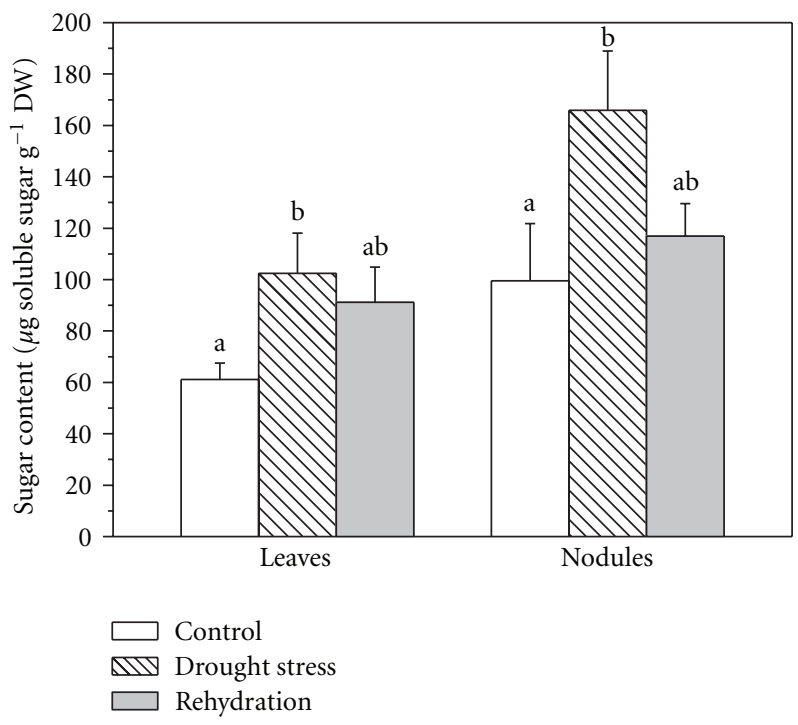

FIGURE 3: Soluble sugar content in leaves and nodules of peanut plants exposed to drought stress and rehydration. Values are means $\pm \mathrm{SE}(n=10)$. Different letters indicate significant differences at $P<0.05$ according to LSD Fisher's test.

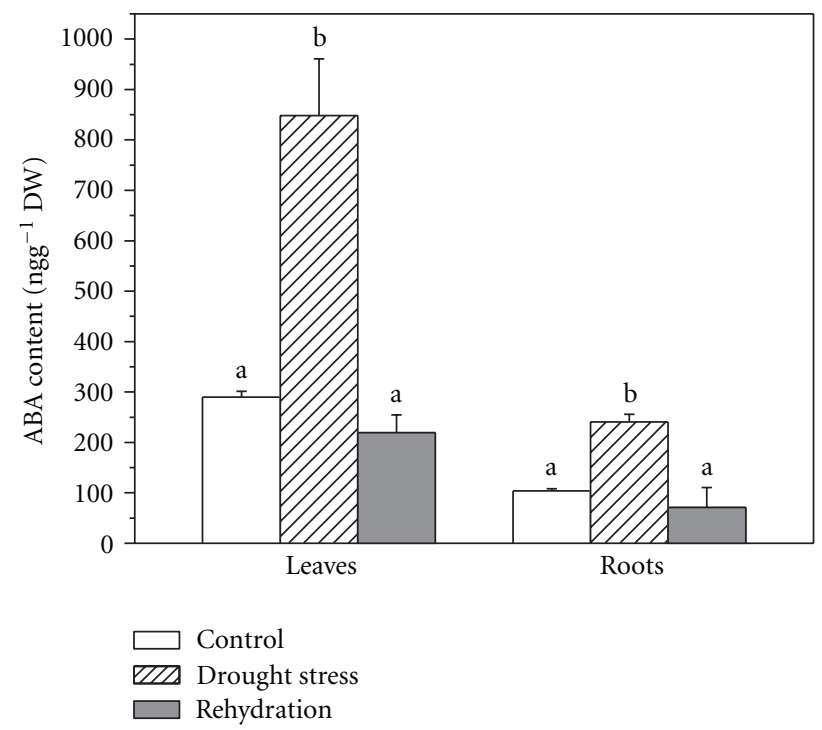

FIGURE 4: ABA content of peanut plants exposed to drought stress and rehydration. Values are means $\pm \mathrm{SE}(n=5)$. Different letters indicate significant differences at $P<0.05$ according to LSD Fisher's test. 


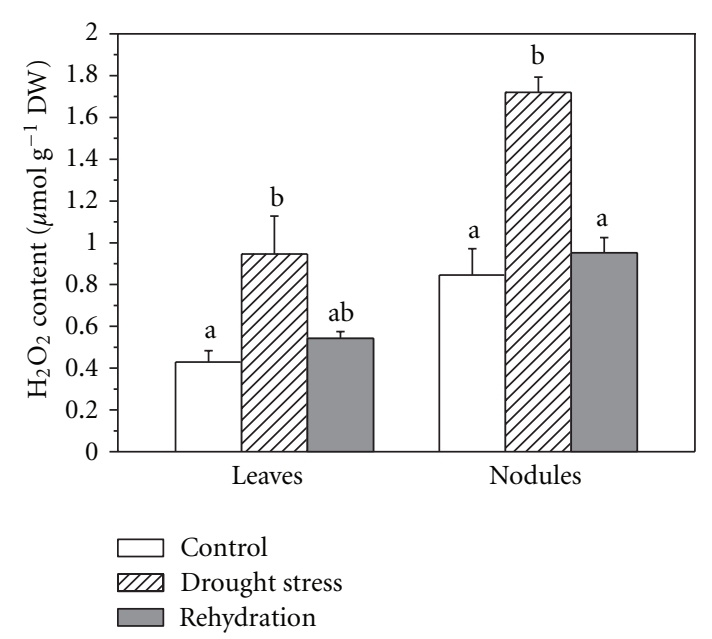

(a)

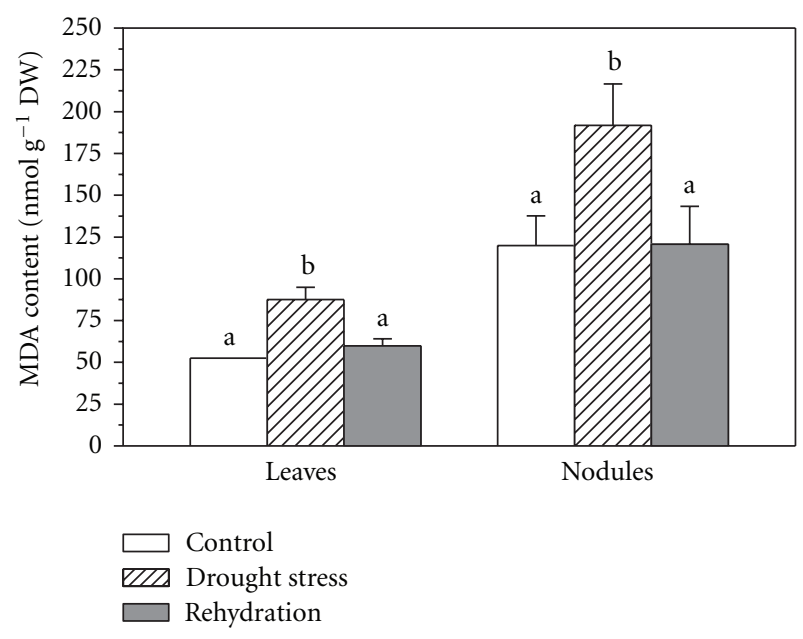

(b)

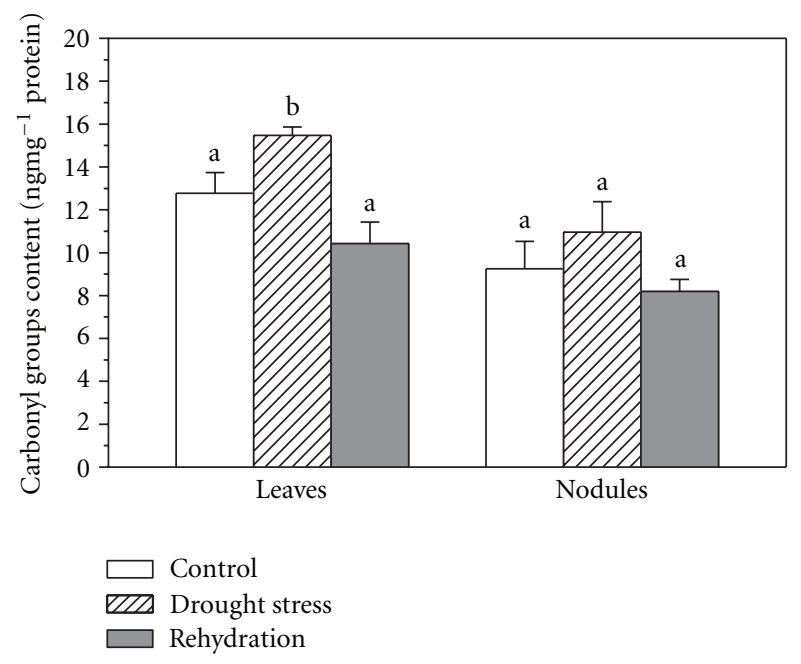

(c)

Figure 5: $\mathrm{H}_{2} \mathrm{O}_{2}$ content (a), MDA content (b), and carbonyl groups content $(\mathrm{c})$ in peanut plants exposed to drought stress and rehydration. Values are means $\pm \operatorname{SE}(n=8)$. Different letters indicate significant differences at $P<0.05$ according to LSD Fisher's test. that is, carbon shortage and nodule carbon metabolism, oxygen limitation, and feedback regulation by the accumulation of $\mathrm{N}$ fixation products [35]. In this work, the symbiotic nitrogen fixation was estimated on the $\mathrm{N}$ content and nodule DW which frequently correlate well with shoot DW, the latter parameter provides an acceptable basis of $\mathrm{N}_{2}$-fixing effectiveness [36]. The results obtained revealed that drought stress caused a decrease in nodulation as well as SNC, and these parameters remained unchanged during the short rehydration period indicating a negative impact of water deficit on symbiotic nitrogen fixation.

Arunyanark et al. [37] reported that stability in peanut chlorophyll content was related to drought tolerance due to the ability to keep constant biomass production, despite unfavourable conditions. Our findings revealed that chlorophyll content maintained unaltered, and this may be related to a higher root biomass production to increase its exploratory surface in order to improve water uptake. Besides, chlorophyll content may allow plants to deliver sufficient energy to deal with the energy-consuming adaptations to drought stress. Another possibility is that chlorophyll has a role in control of redox homoeostasis, that is, collaborates in heat dissipation of excess excitation energy within lightcollecting chlorophyll and the carotenoid-binding protein complexes of photosystem (PS) II, which are considered major photoprotective mechanisms [38]. In this study, chlorophyll content led to an intriguing result, this parameter remained unchanged while nitrogen content decreased, although it is well known that both parameters are tightly related between them [39]. A possible explanation for decrease in foliar $\mathrm{N}$ concentration is attributable to droughtinduced retranslocation of shoot $\mathrm{N}$ to roots or volatilization of foliar $\mathrm{N}$ [40].

Soluble sugar accumulation has been associated with drought tolerance in several plant species [41]. Coueé et al. [42] reported that soluble compounds accumulation may be a tolerance strategy associated with ROSscavenging pathways for survival under stress conditions. Osmotic adjustment is recognized as an effective mechanism associated with drought tolerance, this involves the net accumulation of solutes mainly due to the increase in soluble sugar [43]. As a consequence of this net accumulation, the osmotic potential of the cell is lowered. In this work, independently of the effect of solute concentration due to the water loss from the tissue, both RWC and osmotic potential were used to determine if lower values in osmotic potential could be a consequence of tissue dehydration or osmotic adjustment. Our results showed a low osmotic adjustment (data not shown) suggesting that sugars had a minor role in it, and changes in osmotic potential could be, in part, an indirect result of water lost. Thus, osmotic potential is a good indicator of plant water status and soluble sugar accumulation could be involved, at least partially, in ROS scavenging and signaling response pathways in peanut leaves and nodules under stress conditions.

ABA accumulation has been widely associated with drought stress responses in plants, and interestingly, with plant capacity to keep shoot and root growth under these conditions, in which improved root growth leads to a marked 
benefit in exploration of soil in terms of water search [6]. $\mathrm{ABA}$ accumulation has also been related to increased sugar content due to an enhanced expression of enzymes involved in starch hydrolysis [44]. Therefore, ABA accumulation could be responsible for root growth maintenance and sugar accumulation in stressed peanut plants.

Under stress conditions, hydrogen peroxide generation is essential in cellular signalling due to its role as a second messenger in plant defence [45]. ABA accumulation is known to trigger $\mathrm{H}_{2} \mathrm{O}_{2}$ production as a signal mediating stress tolerance responses [46]. Several studies demonstrated that $\mathrm{ABA}$ accumulation occurs prior to $\mathrm{H}_{2} \mathrm{O}_{2}$ appearance and both molecules are involved in stomatal closure as well as in stomatal opening inhibition [28]. Our results showed that lipid peroxidation and protein oxidation were enhanced in peanut leaves exposed to drought stress while after rehydration those values reached the control values. These indicators of oxidative damage are tightly related to ROS production, evidenced by $\mathrm{H}_{2} \mathrm{O}_{2}$ accumulation, suggesting an oxidative stress under this condition. In stressed peanut nodules, lipid but no protein damage was observed with a concomitant decrease upon rehydration. Naya et al. [47] reported similar results in alfalfa nodules exposed to drought. They concluded that oxidative damage of cellular components jointly with limitations in metabolic capacity of bacteroides would be contributing factors to the reduced $\mathrm{N}$ fixation. Thus, for the symbiotic pair peanut-Bradyrhizobium sp. SEMIA 6144 one of the most relevant findings was the rapid decrease of $\mathrm{H}_{2} \mathrm{O}_{2}$ content when peanut plants were rehydrated in a short period of time (three days) causing the reversion of oxidative stress which may be involved, at least partially, in $\mathrm{N}$ fixation reduction.

\section{Conclusion}

The severe water stress affected negatively peanut growth and nodulation. The enhance of $\mathrm{H}_{2} \mathrm{O}_{2}$ production caused lipid and protein damages; however, the plant was able to increase soluble sugar and ABA contents as avoidance strategies to cope with drought stress. These physiological and biochemical responses were completely reversed upon rehydration in the symbiotic association peanut-Bradyrhizobium sp in a short period of time. Further studies are required to elucidate the entire response pathway, specially the causeeffect relationship between ABA and ROS production in stressed nodulated plants as well as the antioxidant system activity and its implication in ROS removal in rehydrated legume plants.

\section{Acknowledgments}

The authors thank the Secretaría de Ciencia y Técnica, Universidad Nacional de Río Cuarto for providing financial assistance for this research. A. Furlan has a doctoral fellowship from CONICET-MINCyT-Córdoba, A. Llanes has a postdoctoral fellowship, and V. Luna is member of research career of CONICET, Argentina.

\section{References}

[1] T. Y. Reddy, V. R. Reddy, and V. Anbumozhi, "Physiological responses of groundnut (Arachis hypogea L.) to drought stress and its amelioration: a critical review," Plant Growth Regulation, vol. 41, no. 1, pp. 75-88, 2003.

[2] USDA, "United States Department of Agriculture. Foreign Agricultural service. Circular Series WAP 11-11," 2011, http://www.fas.usda.gov/psdonline/circulars/production.pdf.

[3] D. J. Collino, J. L. Dardanelli, R. Sereno, and R. W. Racca, "Physiological responses of argentine peanut varieties to water stress. Light interception, radiation use efficiency and partitioning of assimilates," Field Crops Research, vol. 70, no. 3, pp. 177-184, 2001.

[4] K. Boote and D. Ketring, "Peanut," in Irrigation of Agricultural Crop, Agronomy Monograph, B. Stewart and D. Nielsen, Eds., vol. 30, pp. 675-717, 1990.

[5] J. Zhang, W. Jia, J. Yang, and A. M. Ismail, "Role of ABA in integrating plant responses to drought and salt stresses," Field Crops Research, vol. 97, no. 1, pp. 111-119, 2006.

[6] R. E. Sharp and M. E. Lenoble, "ABA, ethylene and the control of shoot and root growth under water stress," Journal of Experimental Botany, vol. 53, no. 366, pp. 33-37, 2002.

[7] A. Blum, "Crop responses to drought and the interpretation of adaptation," Plant Growth Regulation, vol. 20, no. 2, pp. 135$148,1996$.

[8] T. Moreira, F. S. Henriques, M. C. Matos, and P. S. Campos, "Proto-plasmatic drought resistance and water use efficiency," Bulletin de la Societe Botanique de France, vol. 137, pp. 81-89, 1990.

[9] I. M. Møller, "Plant mitochondria and oxidative stress: electron transport, NADPH turnover, and metabolism of reactive oxygen species," Annual Review of Plant Biology, vol. 52, pp. 561-591, 2001.

[10] K. Asada, "The water-water cycle in chloroplasts: scavenging of active oxygens and dissipation of excess photons," Annual Review of Plant Biology, vol. 50, pp. 601-639, 1999.

[11] L. Guan and J. G. Scandalios, "Two structurally similar maize cytosolic superoxide dismutase genes, Sod4 and Sod4A, respond differentially to abscisic acid and high osmoticum," Plant Physiology, vol. 117, no. 1, pp. 217-224, 1998.

[12] R. Desikan, M. K. Cheung, J. Bright, D. Henson, J. T. Hancock, and S. J. Neill, "ABA, hydrogen peroxide and nitric oxide signalling in stomatal guard cells," Journal of Experimental Botany, vol. 55, no. 395, pp. 205-212, 2004.

[13] J. Yan, N. Tsuichihara, T. Etoh, and S. Iwai, "Reactive oxygen species and nitric oxide are involved in ABA inhibition of stomatal opening," Plant, Cell and Environment, vol. 30, no. 10, pp. 1320-1325, 2007.

[14] M. Matamoros, J. Ramos, and M. Becana, "Especies reactivas de oxígeno y antioxidantes en leguminosas," in Fijación de Nitrógeno: Fundamentos y Aplicaciones, E. J. Bedmar, J. González, C. Lluch, and B. Rodelas, Eds., pp. 221-231, Granada, España, 2006.

[15] U. C. Akcay, O. Ercan, M. Kavas et al., "Drought-induced oxidative damage and antioxidant responses in peanut (Arachis hypogaea L.) seedlings," Plant Growth Regulation, vol. 61 , no. 1, pp. 21-28, 2010.

[16] S. Pimratch, S. Jogloy, N. Vorasoot, B. Toomsan, A. Patanothai, and C. C. Holbrook, "Relationship between biomass production and nitrogen fixation under drought-stress conditions in peanut genotypes with different levels of drought resistance," Journal of Agronomy and Crop Science, vol. 194, no. 1, pp. 15$25,2008$. 
[17] R. Serraj, T. R. Sinclair, and L. C. Purcell, "Symbiotic $\mathrm{N}_{2}$ fixation response to drought," Journal of Experimental Botany, vol. 50, no. 331, pp. 143-155, 1999.

[18] J. Vincent, A Manual for the Practical Study of Root Nodule Bacteria, IBP Handbook No 15, Blackwell Scientific Publication, Oxford, UK, 1970.

[19] D. Hoagland and D. Arnon, "The water culture method for growing plants without soil," California Agricultural Experiment Station Bulletin, vol. 347, pp. 1-39, 1950.

[20] SSL, Soil Survey Laboratory and R. Burk, "Soil survey laboratory methods manual," Soil Survey Investigations Report 42, Vers 3.0, National Soil Survey Center, Lincoln, Ne, USA, 1996.

[21] K. Boote, "Growth stages of peanut (Arachis hypogaea L.)," Peanut Science, vol. 9, pp. 35-40, 1982.

[22] H. Barr and P. Weatherley, "A re-examination of the relative turgidity technique for estimating water deficit in leaves," Australian Journal of Biological Science, vol. 15, pp. 413-428, 1962.

[23] R. Sayar, H. Khemira, A. Kameli, and M. Mosbahi, "Physiological tests as predictive appreciation for drought tolerance in durum wheat (Triticum durum Desf.)," Agronomy Research, vol. 61, pp. 70-90, 2008.

[24] M. Udayakumar, R. Devendra, G. Ramaswamy et al., "Measurement of transpiration efficiency under field conditions in grain legume crops," Plant Physiology and Biochemistry, vol. 1, pp. 69-75, 1998.

[25] D. Nelson and L. Sommers, "Determination of total nitrogen in plant material," Agronomy Journal, vol. 65, pp. 109-112, 1973.

[26] D. Arnon, "Copper enzymes in chloroplasts polyphenoloxydases in Beta vulgaris," Plant Physiology, vol. 24, pp. 1-15, 1949.

[27] M. T. Colinas León, I. A. Tejacal, C. B. Bañuelos, and L. A. Valdez Aguilar, "Fluctuación de carbohidratos durante el desarrollo de nochebuena (Euphorbia pulcherrima Willd) en dos localidades," Revista Fitotecnia Mexicana, vol. 29, pp. 6368, 2006.

[28] Z. Dische, "General color reactions," Methods in Carbohydrate Chemistry, vol. 1, pp. 478-492, 1962.

[29] R. Zhou, T. M. Squires, S. J. Ambrose, S. R. Abrams, A. R. S. Ross, and A. J. Cutler, "Rapid extraction of abscisic acid and its metabolites for liquid chromatography-tandem mass spectrometry," Journal of Chromatography A, vol. 1010, no. 1, pp. 75-85, 2003.

[30] V. Alexieva, I. Sergiev, S. Mapelli, and E. Karanov, "The effect of drought and ultraviolet radiation on growth and stress markers in pea and wheat," Plant, Cell and Environment, vol. 24, no. 12, pp. 1337-1344, 2001.

[31] R. L. Heath and L. Packer, "Photoperoxidation in isolated chloroplasts. I. Kinetics and stoichiometry of fatty acid peroxidation," Archives of Biochemistry and Biophysics, vol. 125, no. 1, pp. 189-198, 1968.

[32] R. L. Levine, D. Garland, C. N. Oliver et al., "Determination of carbonyl content in oxidatively modified proteins," Methods in Enzymology, vol. 186, pp. 464-478, 1990.

[33] G. C. Wright and R. C. Nageswara Rao, "Groundnut water relations," in The Groundnut Crop. A Scientific Basis for Improvement, J. Smartt, Ed., pp. 281-325, Chapman and Hall, London, UK, 1994.

[34] D. Puangbut, S. Jogloy, N. Vorasoot et al., "Association of root dry weight and transpiration efficiency of peanut genotypes under early season drought," Agricultural Water Management, vol. 96, no. 10, pp. 1460-1466, 2009.
[35] R. Serraj, "Effects of drought stress on legume symbiotic nitrogen fixation: physiological mechanisms," Indian Journal of Experimental Biology, vol. 41, no. 10, pp. 1136-1141, 2003.

[36] P. Somasegaran and H. Hoben, "Quantifying the growth of Rhizobia," in Handbook for Rhizobia, pp. 165-169, Springer, New York, USA, USA, 1994.

[37] A. Arunyanark, S. Jogloy, C. Akkasaeng et al., "Chlorophyll stability is an indicator of drought tolerance in peanut," Journal of Agronomy and Crop Science, vol. 194, no. 2, pp. 113125, 2008.

[38] K. K. Niyogi, "Photoprotection revisited: genetic and molecular approaches," Annual Review of Plant Biology, vol. 50, pp. 333-359, 1999.

[39] B. Bojović and A. Marković, "Correlation between nitrogen and chlorophyll content in wheat (Triticum aestivum L.)," Kragujevac Journal of Science, vol. 31, pp. 69-74, 2009.

[40] S. A. Heckathorn, E. H. DeLucia, and R. E. Zielinski, "The contribution of drought-related decreases in foliar nitrogen concentration to decreases in photosynthetic capacity during and after drought in prairie grasses," Physiologia Plantarum, vol. 101, no. 1, pp. 173-182, 1997.

[41] A. Al Hakimi, P. Monneveux, and G. Galiba, "Soluble sugars, proline and relative water content (RWC) as traits for improving drought tolerance and divergent selection for RWC from T. polonicum into T. durum," Journal of Genetics and Breeding, vol. 49, pp. 237-244, 1995.

[42] I. Couée, C. Sulmon, G. Gouesbet, and A. El Amrani, "Involvement of soluble sugars in reactive oxygen species balance and responses to oxidative stress in plants," Journal of Experimental Botany, vol. 57, no. 3, pp. 449-459, 2006.

[43] J. M. Morgan, "Osmotic components and properties associated with genotypic differences in osmoregulation in wheat," Austral Journal of Plant Physiology, vol. 19, pp. 67-76, 1992.

[44] M. Ghassemian, J. Lutes, H. S. Chang et al., "Abscisic acidinduced modulation of metabolic and redox control pathways in Arabidopsis thaliana," Phytochemistry, vol. 69, no. 17, pp. 2899-2911, 2008.

[45] M. H. Cruz De Carvalho, "Drought stress and reactive oxygen species: production, scavenging and signaling," Plant Signaling and Behavior, vol. 3, no. 3, pp. 156-165, 2008.

[46] Y. Xing, W. Jia, and J. Zhang, "AtMKK1 mediates ABA-induced CAT1 expression and $\mathrm{H}_{2} \mathrm{O}_{2}$ production via AtMPK6-coupled signaling in Arabidopsis," Plant Journal, vol. 54, no. 3, pp. 440$451,2008$.

[47] L. Naya, R. Ladrera, J. Ramos et al., "The response of carbon metabolism and antioxidant defenses of alfalfa nodules to drought stress and to the subsequent recovery of plants," Plant Physiology, vol. 144, no. 2, pp. 1104-1114, 2007. 


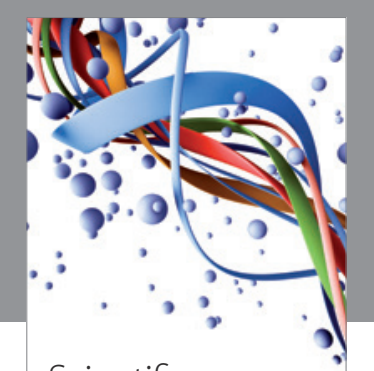

Scientifica
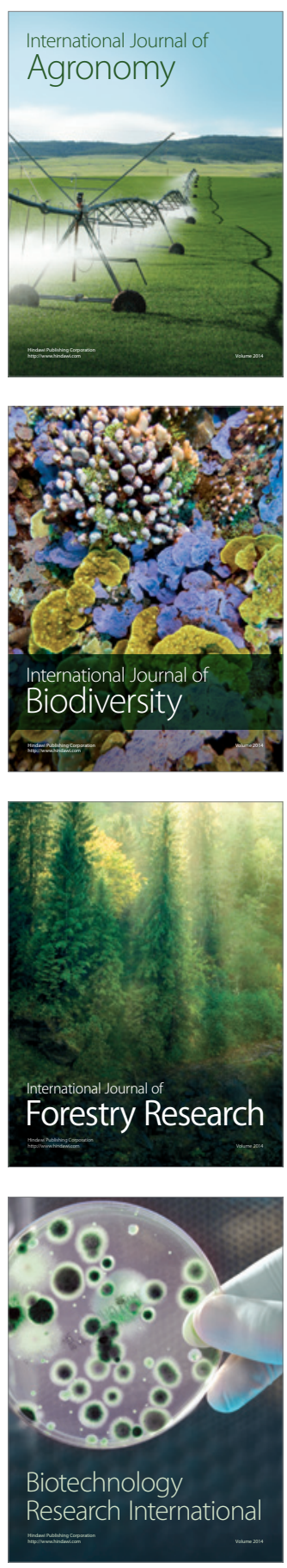
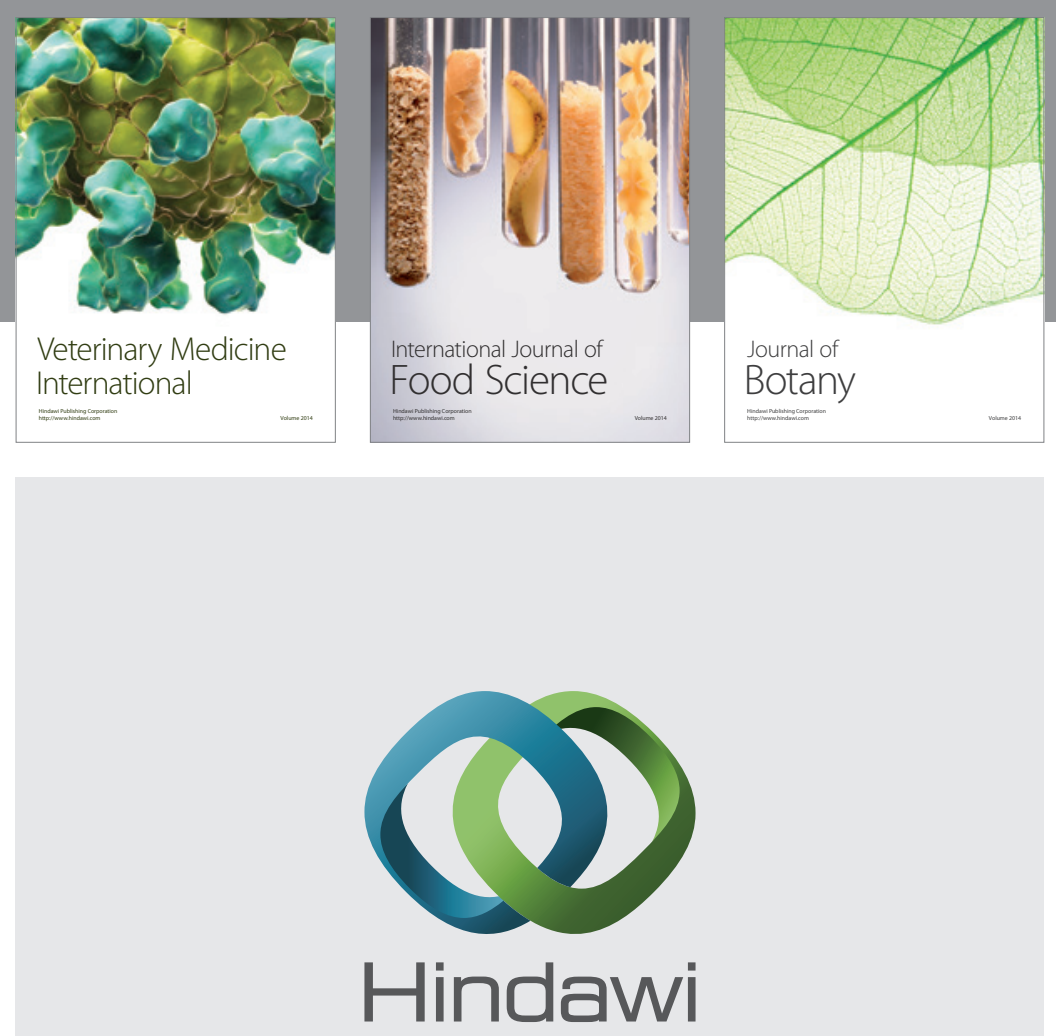

Submit your manuscripts at

http://www.hindawi.com
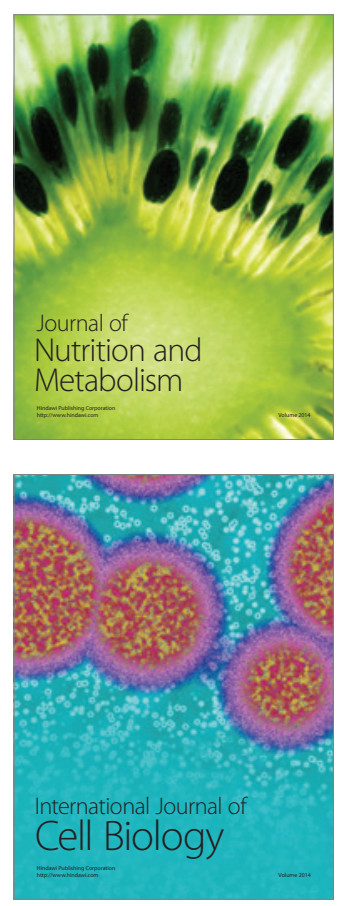
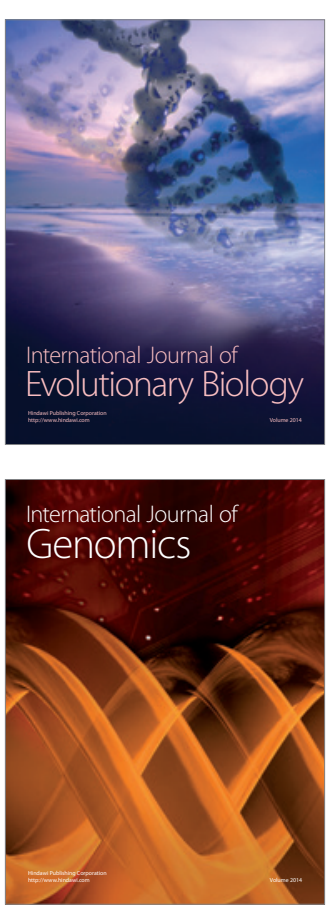
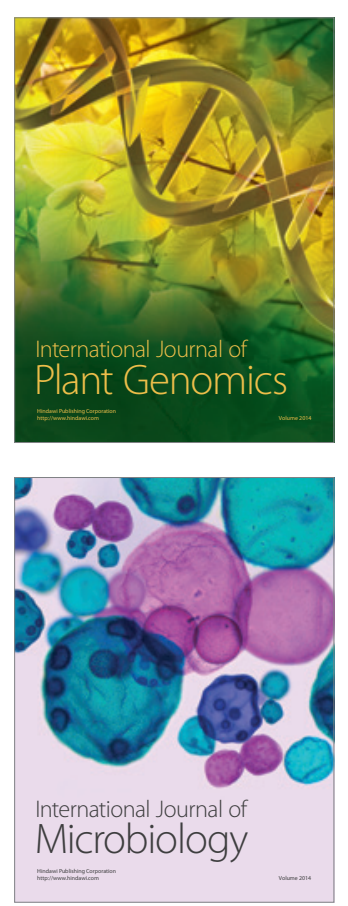

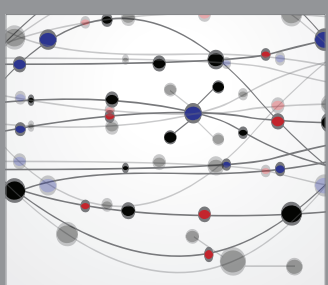

The Scientific World Journal
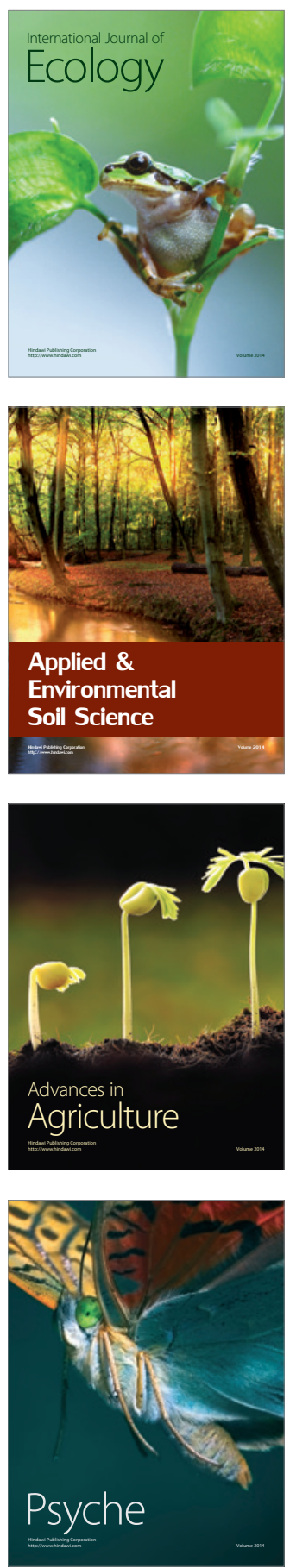